\title{
Evaluation of individual fungal species and their co-culture for degrading a binary mixture of dyes under solid-state fermentation
}

\author{
Sara Jiménez Correa ${ }^{(1)}$, Ana Cristina Jaramillo ${ }^{(2)}$, Rubiel Andrés Merino ${ }^{(1)}$, \\ Angelina Hormaza ${ }^{(1)}$ \\ (1) Universidad Nacional de Colombia - Sede Medellín. Carrera 65 Nro. 59A -110. 21-239 Medellin (Colombia). E-mail: \\ sjimenezc@unal.edu.co \\ (2) University of Technology Sydney. 15 Broadway. Ultimo NSW 2007. Sydney (Australia).
}

Received March 9, 2018; accepted September 18, 2018; available online 23 October 2018.

This article is distributed under the terms and conditions of the CC-BY License (http://creativecommons.org/licenses/by/4.0)

Description of the subject. In recent years, biological methodologies, such as solid-state fermentation, have acquired a great relevance for bioremediation of complex molecules because of their efficiency and low environmental impact. Specifically, the use of white-rot fungi in different biotechnological processes has emerged as a promising strategy given their broad enzymatic potential.

Objectives. Evaluation of three individual fungal species, as well as various fungal consortia of these species, for the degradation of a mixture of dyes, brilliant blue - allura red, through solid-state fermentation.

Method. The species Pleurotus pulmonarius, Pleurotus ostreatus and Trametes versicolor were assessed, both individually, and in their binary consortia. The interaction between the mycelia of the different white-rot fungi was taken into account as a criterion for using their consortia to degrade the mixture of pollutants under solid conditions. The dyes were adsorbed onto the agro-industrial by-products flower stems and corncob. The fermentative process was carried out over 20 days, after which the degradation percentage was quantified by UV-Vis spectroscopy.

Results. The highest degradation percentage was obtained after fermentation by $T$. versicolor alone. This species reached an average degradation of $79.57 \%$ of the binary mixture of dyes, brilliant blue - allura red. Meanwhile, the best consortium, composed of P. ostreatus and T. versicolor, achieved a degradation of $63.24 \%$.

Conclusions. These results suggest that the use of fungal consortia, in solid media, does not always lead to a synergy between species for improved dye degradation by the integrated strategy that includes the processes of adsorption and solid-state fermentation. Instead, competition for space and nutrients associated with growth on a solid substrate could decrease the degradation efficiency.

Keywords. Biodegradation, industrial pollutants, Basidiomycota, adsorbents, desorption.

Évaluation des espèces fongiques individuelles et de leurs consortiums pour la dégradation d'un mélange binaire de colorants dans des conditions de fermentation à l'état solide

Description du sujet. Ces dernières années, les méthodes biologiques, telles que la fermentation à l'état solide, ont acquis une grande importance pour la biorestauration de molécules complexes en raison de leur efficacité et de leur faible impact environnemental. Plus précisément, l'utilisation de champignons responsables de la pourriture blanche dans différents processus biotechnologiques est devenue une stratégie prometteuse, compte tenu de leur potentiel enzymatique étendu.

Objectifs. Évaluation de trois espèces de champignons, ainsi que de divers consortiums fongiques de ces espèces, pour la dégradation d'un mélange de colorants, le bleu brillant - rouge allura, par fermentation à l'état solide.

Méthode. Les espèces Pleurotus pulmonarius, Pleurotus ostreatus et Trametes versicolor ont été évaluées, à la fois individuellement et dans leurs consortiums binaires. L'interaction entre les mycéliums des différents champignons de la pourriture blanche a été prise en compte comme critère d'utilisation de leurs consortiums pour dégrader le mélange de polluants dans des conditions solides. Les colorants ont été adsorbés sur les tiges florales et les épis de maïs des sous-produits agro-industriels. Le processus de fermentation a été effectué sur 20 jours, ensuite le pourcentage de dégradation a été quantifié par spectroscopie UV-Vis. 
Résultats. Le pourcentage de dégradation le plus élevé a été obtenu après fermentation par T. versicolor seul. Cette espèce a atteint une dégradation moyenne de 79,57 \% du mélange binaire de colorants, le bleu brillant - rouge allura. Pendant ce temps, le meilleur consortium, composé de P. ostreatus et T. versicolor, a obtenu une dégradation de 63,24\%.

Conclusions. Ces résultats suggèrent que l'utilisation de consortiums de champignons, dans des milieux solides, n'entraine pas toujours une synergie entre les espèces pour améliorer la dégradation des colorants grâce à la stratégie intégrée qui inclut les processus d'adsorption et de fermentation à l'état solide. Au lieu de cela, la concurrence pour l'espace et les nutriments associés à la croissance sur un substrat solide pourrait diminuer l'efficacité de la dégradation.

Mots-clés. Biodégradation, polluant industriel, Basidiomycotina, adsorbant, désorption.

\section{INTRODUCTION}

The use of synthetic dyes in pharmaceutical, food and textile industries has dramatically increased over the last times. Indeed, there are over 10,000 dyes currently available, and global annual production exceeds $7 \times 10^{5}$ metric tons (Dyes - pigments by Standardcon, 2018). Previous studies suggest that about $80 \%$ of these molecules are consumed during the dyeing process, generating large volumes of colored effluents, which are usually discharged in water sources with a minimal treatment (Forgacs et al., 2004). Furthermore, the aromatic moieties of these molecules are resistant to degradation by light, water and many chemical compounds, making them difficult to treat once they are released into aquatic ecosystems (Robinson et al., 2002). The lasting presence of dyes in these ecosystems cannot be ignored, as a decreased of water transparency negatively affects both photosynthetic processes and gas solubility (Banat et al., 1996).

Brilliant blue (BB), a triphenylmethane dye widely used in textile dyeing, is characterized by its high solubility and the presence of three sulfonate groups (Gupta et al., 2006). Its toxicity has been demonstrated through detection of fibrosarcomas in rodents exposed to subcutaneous injections of $30 \mathrm{mg}$ of this dye (Hansen et al., 1966). Allura red (AR) is another widely used dye, prevalent in the food and textile industries for its low-cost (Soylak et al., 2011). It has also been demonstrated as toxic through physical and behavioral assessments of mice dosed with AR at up to $10 \%$ of their diet (Vorhees et al., 1983). Allura red contains an azo functional group and aromatic ring structures, all of which are harmful to human health, as they induce allergies and neurological disorders. It is clear that applying efficient and low-cost methods for treating effluents that contain such pollutants is crucial, both for ecological importance as well as human health.

Adsorption using agro-industrial by-products has been demonstrated as an efficient and low-cost physicochemical technology to remove dissolved dyes from aqueous solutions, achieving removal percentages over 90\% (Gupta \& Suhas, 2009; Echavarria-Alvarez \& Hormaza-Anaguano, 2014; Sulyman et al., 2017). More recently, solid-state fermentation (SSF), a biological process dependent on living microbes, has acquired great interest because of its minimal environmental impact. In fact, there are many studies that report its use in the bioremediation of several pollutants, including synthetic dyes (Robinson \& Nigam, 2008; Ijoma \& Tekere, 2017; Jaramillo et al., 2017). Furthermore, SSF has other desirable applications, particularly regarding the biotechnological production of enzymes, organic acids, antibiotics, biofuels and secondary metabolites.

Solid-state fermentation offers numerous advantages, including low-cost, decreased catabolic repression, production of high value metabolites, lower sterility conditions than the required in submerged fermentation, and the culture of specialized microorganisms for water insoluble substrates (Singhania et al., 2009). Furthermore, SSF occurs under conditions which are appropriate for the growth of filamentous fungi, such as white-rot fungi (WRF) (Singhania et al., 2009; Thomas et al., 2013). These fungi are characterized by the production of extracellular oxidative enzymes, some of which are involved in the cleavage of lignin, one of the main polymers present in agricultural biomass (Wesenberg et al., 2003). In this way, WRF provides an appealing platform for the bioremediation of synthetic dyes, whose chemical structures are simpler than lignocellulosic polymers, when grown under SSF conditions (Chander \& Arora, 2007; Ijoma \& Tekere, 2017; Jaramillo et al., 2017).

While WRF grown under SFF conditions have many benefits over conventional decontamination methods, there is evidence to suggest that using a WRF consortium could be even more efficient. Using a consortium could provide improved colonization of the substrate, increased production of relevant enzymes and greater resistance to contamination by other microorganisms (Kausar et al., 2010; Ijoma \& Tekere, 2017). Indeed, several authors have reported that the most important parameters in mixed cultures are species compatibility and nutritional factors (Castillo et al., 1994; Gutierrez-Correa et al., 1999). Species compatibility influences the efficiency of substrate break down through various types of species interaction (Windram et al., 2016). These interactions occur when fungal hyphae from different mycelia grow towards each other, resulting in three main types of interaction: mutual intermingling, inhibition and 
mutual intermingling plus inhibition. With regard to nutrition, the carbon source, the nature of the nitrogen, and the ratio between these two components $(\mathrm{C}: \mathrm{N})$, all play an important role in the metabolism of microorganisms grown in a consortium.

To date, there are few reports which have assessed the use of fungal consortia for degradation of synthetic dyes. Verma \& Madamwar (2002) investigated the use of an enzyme extract obtained from the co-cultivation of Pleurotus ostreatus and Phanerochaete chrysosporium under SSF conditions, demonstrating degradation efficiencies over $70 \%$ for several dyes of different chemical structure (Verma \& Madamwar, 2002). Meanwhile, Kuhar et al. (2015) demonstrated faster degradation rates of malachite green dye using the consortium Ganoderma lucidum Trametes versicolor, compared to conditions in which these species were used alone. Here, co-culture conditions were conducted by mixing and processing equal amounts of SSF media of each strain (Kuhar et al., 2015). However, it is possible that the type of inoculum could affect the interactions between the species, though further studies that support this issue are needed. It is important to consider that these studies have focused on degrading individual dyes alone and that in most cases, industrial effluents contain binary or even multi-component mixtures of these pollutants. In this respect, few investigations have focused on the use of WRF consortia for the treatment of dye pollutants in their real-life context, such as in industrial effluents. One such example, which investigated the treatment of a group of reactive dyes with mixed cultures of Trametes villosa and Pycnoporus sanguineus, reported a degradation efficiency of $90 \%$, using submerged fermentation conditions (Machado et al., 2006).

Given this context, the aim of the present work was to treat synthetic dyes under solid-state fermentation conditions using WRF consortia compared to the WRF individual species alone. The degradation of the binary mixture of dyes BB (adsorbed onto flower stems, FS) and AR (adsorbed onto corncob, CC) was evaluated. The individual species, Pleurotus pulmonarius, Pleurotus ostreatus and Trametes versicolor, and their three binary consortia, were used under SSF conditions. To our knowledge, this is also the first work that analyzes hyphae interactions and percentage of mycelial growth as criteria for fungal consortia selection. The adsorption of $\mathrm{BB}$ and $\mathrm{AR}$ has been previously optimized onto the corresponding agroindustrial by-products in our research group (Moreno et al., 2012; Jaramillo et al., 2013).

\section{MATERIALS AND METHODS}

\subsection{Microorganisms and maintenance}

The species of WRF, Pleurotus ostreatus ("Pearl Oyster"), Pleurotus pulmonarius ("Phoenix Oyster") and Trametes versicolor (DSM 3086), were obtained from the Faculty of Exact and Natural Sciences at Universidad de Antioquia. They were maintained at $4{ }^{\circ} \mathrm{C}$ on potato dextrose agar plates and subcultured every month.

\subsection{Dyes adsorption}

Both agro-industrial by-products, FS and CC, were obtained from a local market in Medellín, Antioquia, Colombia. Their pre-treatment included milling, sieving (particle size 0.3-0.7 mm), washing and drying (Moreno et al., 2012; Jaramillo et al., 2013).

Brilliant blue, also known as acid blue 9 (Figure 1a) has as color index 42090. This anionic dye registers its maximum absorption wavelength at $629 \mathrm{~nm}$. It is able to form up to ten hydrogen bonds, promoting its high solubility in water. For the adsorption process, 11 of BB solution at a concentration of $12 \mathrm{mg} \cdot \mathrm{l}^{-1}$ was prepared and put in contact with $8 \mathrm{~g}$ of FS in a 11 Erlenmeyer flask under continuous stirring at room temperature for $120 \mathrm{~min}$. The conditions that maximize this adsorption process under batch system were previously obtained by Jaramillo et al. (2013).

Allura red or red 40 (Figure 1b) has a color index 16035. Allura red is an anionic dye with a wavelength of maximum absorption of $502 \mathrm{~nm}$ and it can accept up to ten hydrogen bonds, which allow the solubility of the molecule in water. To retain this dye in the agro-industrial waste $\mathrm{CC}, 11$ of AR solution with a concentration of $44 \mathrm{mg} \cdot \mathrm{l}^{-1}$ was mixed with $10 \mathrm{~g}$ of CC in a 11 Erlenmeyer flask under continuous stirring at
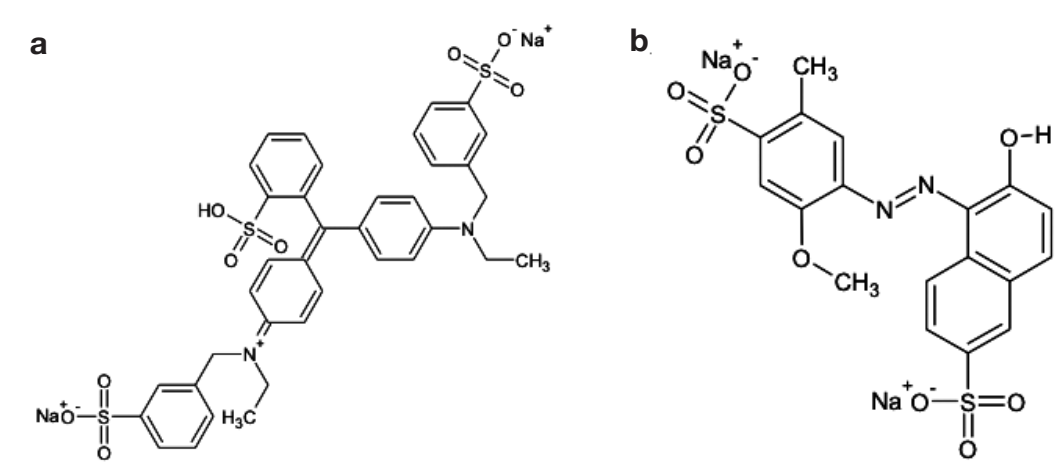

Figure 1. Structure of dyes - Structure des colorants.

a. Brilliant blue - bleu brillant; b. Allura red - rouge allura; source: own production in ACD/ChemSketch 2016.2.2, Freeware version - production des auteurs dans ACD/ChemSketch 2016.2.2, version Freeware. 
room temperature for $120 \mathrm{~min}$. The optimal conditions for this adsorption process operating in batch system were earlier reported by Moreno et al. (2012).

Once the contact time was completed for the adsorption of each dye, the dyed adsorbent was separated from the residual solution by filtration. The absorbance of the residual solution was measured in a Perkin Elmer UV-Vis Lambda 35 double beam spectrophotometer, at the maximum absorption wavelength for each dye. The amount of retained dye in the adsorbent material was determined by Eq. (1) for each system waste-dye, where $C_{i}$ and $C_{f}$ are the initial and final concentrations of the solutions, respectively:

$$
\% R=\frac{C_{i}-C_{f}}{C_{i}} \times 100
$$

\subsection{Solid-state fermentation}

The solid substrate for the SSF process was prepared by mixing both dyed materials, DM, in a ratio $1: 1$ in weight. The fermentation was carried out in $50 \mathrm{ml}$ Erlenmeyer flasks containing $0.5 \mathrm{~g}$ of DM, a C:N ratio of $30: 1$, a moisture content of $75 \%$, wet basis, at $25^{\circ} \mathrm{C}$ for 20 days.

Bromatological analyses of FS and CC were conducted at the Chemical and Bromatological Analysis Laboratory of Universidad Nacional de Colombia - Sede Medellin (Table 1). The determination of the main components of the adsorbents was made according to Van Soest method (Van Soest $\&$ Wine, 1968), and included the measurement of acid detergent fiber, neutral detergent fiber, and lignin. This information allowed to estimate the content of cellulose and hemicellulose. The fractions of nitrogen and carbon were taken from Membrillo et al. (2008); thus, $16 \%$ of protein is considered as nitrogen and $40 \%$ of carbohydrate as carbon; and taking into account

Table 1. Composition analysis of agro-industrial byproducts - Analyse de la composition des sous-produits agro-industriels.

\begin{tabular}{lll}
\hline Analyzed components & Corncob (\%) & Flower stems (\%) \\
\hline Acid detergent fiber & 57.13 & 67.80 \\
Neutral detergent fiber & 85.34 & 77.90 \\
Lignin & 7.39 & 17.60 \\
Nitrogen & 0.60 & 0.90 \\
Hemicellulose & 28.21 & 10.10 \\
Cellulose & 49.74 & 50.20 \\
\hline
\end{tabular}

Hemicellulose - hémicellulose: neutral detergent fiber, lignin, cellulose - fibres insolubles dans les détergents neutres, lignine, cellulose; cellulose - cellulose: acid detergent fiber, lignin - fibres insolubles dans les détergents acides, lignine. the amount of retained dye in the by-product, the C:N ratio of DM was 47:1. Therefore, to adjust this ratio, a nutrient solution with $0.0179 \mathrm{mg} \cdot \mathrm{l}^{-1}$ of yeast extract as nitrogen source and $0.5 \mathrm{mM} \mathrm{CuSO} \cdot 5 \mathrm{H}_{2} \mathrm{O}$ as inductor of the ligninolytic enzymes was added (Baldrian \& Gabriel, 2002). Even though $\mathrm{Cu}^{2+}$, as well as other metal ions, for instance, $\mathrm{Ag}^{+}, \mathrm{Cd}^{2+}$ and $\mathrm{Hg}^{2+}$, can be highly toxic for the organism, the toxicity depends on the concentration selected. Galhaup \& Haltrich (2001) demonstrated that concentrations between 0.1-1.0 mM of $\mathrm{CuSO}_{4} \cdot 5 \mathrm{H}_{2} \mathrm{O}$ do not inhibit growth when they are added at the beginning of the fermentation (Galhaup \& Haltrich, 2001).

The fungal inoculum was taken from wheat bran agar and the solid medium was supplemented with malt extract (Jaramillo et al., 2014). To achieve conditions of $75 \%$ moisture, $2.6 \mathrm{ml}$ water. $\mathrm{g}^{-1} \mathrm{DM}$ must be added. Thus, $1 \mathrm{ml}$ of nutrient solution and $0.3 \mathrm{ml}$ of $6.6 \mathrm{~g} \cdot \mathrm{l}^{-1}$ malt extract solution were supplemented to the $0.5 \mathrm{~g} \mathrm{DM}$.

\subsection{Desorption}

Once the fermentation process was finished, the degradation percentage was determined through the desorption of the non-degraded dyes impregnated onto the agro-industrial by-product. Thirty-five milliliters of $0.005 \mathrm{M} \mathrm{KOH}$ solution were added to each Erlenmeyer flask and stirred at $140 \mathrm{rpm}$ for $2 \mathrm{~h}$ in a Heidolph Unimax 2010 shaker. These conditions were previously determined in our research group for each system waste-dye by-product. The residual solution is a binary mixture of BB-AR and because the wavelength of maximum absorption of each dye was not shifted, the absorbance at these wavelengths can be correlated with the concentration of each component in the mixture and the desorbed amount, $W_{d}$, can be quantified.

Given that this process is not $100 \%$ effective in the removal of residual dyes from the agro-industrial by-product, the desorption efficiency, eff, for each individual dye was calculated by Eq. (2), where $W_{a}$ is the amount of dye impregnated into the waste after adsorption process, and $W_{d c}$ is the desorbed dye in the abiotic control of DM. Thus, the total non-degraded dye, $W_{t}$, was determined by Eq. (3), where $W_{d}$ is the desorbed dye. Finally, the degradation percentage of each dye, \%D, was estimated by Eq. (4):

$$
\begin{gathered}
\text { eff }=\frac{W_{d c}}{W_{a}} \\
W_{t}=\frac{W_{d}}{e f f}
\end{gathered}
$$




$$
\% D=\frac{W_{a}-W_{t}}{W_{a}} \times 100
$$

\subsection{Evaluation of the interaction between fungal species}

The species T.versicolor, P.ostreatus and $P$. pulmonarius were combined to obtain three fungal consortia, detailed in table 2.

Interactions between species within each of the fungal consortia were assessed by the percentage of mycelial growth, \%MG. This test was carried out on solid-agar with $20 \mathrm{~g} \cdot \mathrm{l}^{-1}$ malt extract, $0.1 \mathrm{~g} \cdot \mathrm{l}^{-1} \mathrm{AR}$, $0.1 \mathrm{~g} \cdot \mathrm{l}^{-1} \mathrm{BB}$ and $15 \mathrm{~g} \cdot \mathrm{l}^{-1}$ agar. In the case of fungal consortia, the medium was inoculated with two fungal mycelium plugs, one from each species (according to table 2). The plugs were equidistantly placed apart, and the growth of each species was measured. As a control for each species, the same medium was inoculated with a single plug of mycelium located at the center of the Petri dish, and the free growth was measured.

The diameter of the mycelium plugs was $0.5 \mathrm{~cm}$; each assay was performed in triplicate and the Petri dishes were incubated during eight days at $28{ }^{\circ} \mathrm{C}$. The diameter of mycelial growth was measured daily. The percentage of mycelial growth, \%MG, was determined with Eq. (5):

$$
\% M G=\frac{G_{c}}{G_{F}} \times 100
$$

where $G_{C}$ is the diameter of growth in the consortium and $G_{F}$ is the diameter of free growth. After eight days, each individual species had colonized the whole Petri dish, that is, $G_{F}$ was $8.4 \mathrm{~cm}$ in all the cases.

\subsection{Statistical analyses}

To determine statistical differences between means, a test of multiple comparisons through Scheffé's method $(\alpha=0.05)$ was used. Shapiro-Wilk and Levene tests were performed to determine the validity of the analysis of variance, with a confidence level of $99 \%$, verifying the criteria of normality and homoscedasticity, respectively. All results are reported as the average of measurements plus or minus $( \pm)$ the standard deviation.

Table 2. Assessed white-rot fungi in fungal consortia - Champignons de la pourriture blanche évalués dans les consortiums fongiques.

\begin{tabular}{ll}
\hline Consortium & Species \\
\hline A & Pleurotus ostreatus - Pleurotus pulmonarius \\
B & Pleurotus ostreatus - Trametes versicolor \\
C & Pleurotus pulmonarius - Trametes versicolor \\
\hline
\end{tabular}

The number of observations for each run was nine, corresponding to each of the three species with three replicates. A similar procedure was implemented with the three consortia. Analyses were performed in R 3.2.3 (R Development Core Team, 2015) and the package "agricolae" was used (de Mendiburu, 2015).

\section{RESULTS}

\subsection{Adsorption and desorption}

A removal of $78.75 \%$ for BB and $94.04 \%$ for AR was achieved. The quantity of dye per gram of adsorbent was $1.13 \mathrm{mg} \mathrm{BB} \cdot \mathrm{g}^{-1} \mathrm{FS}$ and $4.33 \mathrm{mg} \mathrm{AR} \cdot \mathrm{g}^{-1} \mathrm{CC}$. The efficiency of the desorption process was 0.86 for each dye in the mixture. As described in the methodology, this value was taken into account for the final calculation of the degradation of the two dyes to avoid an overestimation in the degradation efficiency.

The quantification of the dyes after desorption represents a challenge, given that the residual solution is a binary mixture of dyes. In this case three situations are possible: no overlapping bands, partially overlapping bands and completely overlapping bands (Turabik, 2008). The absorption spectra of both dyes are partially overlapped, as it can be seen in figure 2 . The quantification of $\mathrm{BB}$ and $\mathrm{AR}$ in mixture has been already studied (Villada \& Hormaza, 2015; Jiménez et al., 2017) and it is performed through a mathematical model.

\subsection{Degradation of the binary mixture of dyes with individual species under SSF conditions}

The mixture of dyes BB-AR was degraded using the fungi T.versicolor, P. ostreatus and P.pulmonarius. The degradation percentage of each dye was quantified by Eq. (4) and the results are shown in table 3. Scheffé's

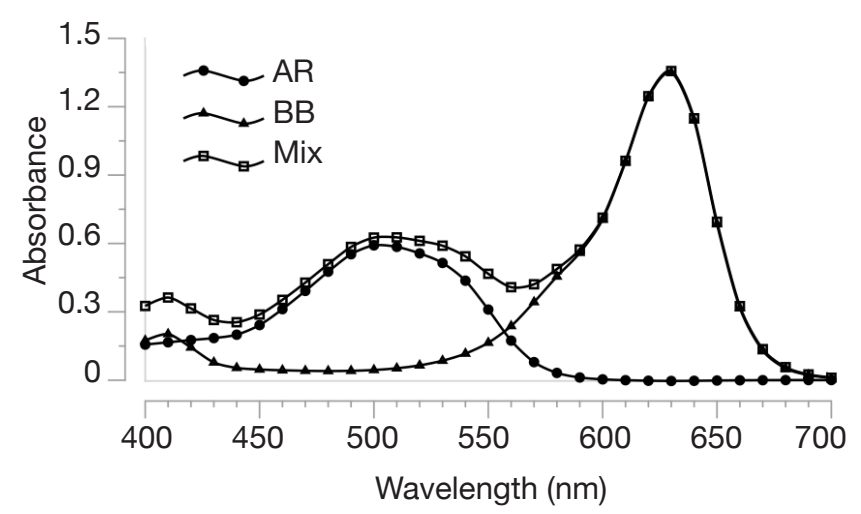

Figure 2. Absorption spectra of both the individual dyes and the binary mixture of dyes - Spectres d'absorption des deux colorants individuels et du mélange binaire de colorants. 
Table 3. Degradation percentage of each dye by the individual species - Pourcentage de dégradation de chaque colorant par les espèces individuelles.

\begin{tabular}{lll}
\hline Species & $\begin{array}{l}\text { \%D of brilliant } \\
\text { blue }\end{array}$ & $\begin{array}{l}\text { \%D of allura } \\
\text { red }\end{array}$ \\
\hline Trametes versicolor & $78.86 \pm 5.56^{\mathrm{a}}$ & $80.28 \pm 3.08^{\mathrm{d}}$ \\
\hline $\begin{array}{l}\text { Pleurotus ostreatus } \\
\begin{array}{l}\text { Pleurotus } \\
\text { pulmonarius }\end{array}\end{array}$ & $62.96 \pm 4.49^{\mathrm{b}}$ & $39.97 \pm 0.80^{\mathrm{e}}$ \\
\hline
\end{tabular}

The means with the same letter are not significantly different at $5 \%$ (Scheffé's test) - les moyennes surmontées d'une même lettre ne sont pas significativement différentes à $5 \%$ (test de Scheffé).

test showed that all treatments were significantly different for $\mathrm{BB}$, which is marked with different letter subscripts. For AR, the species P.ostreatus and $P$. pulmonarius did not exhibit significant differences.

\subsection{Evaluation of the interaction between the fungal species}

The mycelial interactions in each consortium after eight days of culture are presented in figure 3. Non-mutual intermingling was observed, whereby the border between the two mycelia becomes unrecognizable and, as is the case here, a defined borderline within the species can be observed in the three fungal consortia (Figure 3). In this study, no inhibition zone free of hyphae was detected, therefore inhibition did not occur. In cases where mutual intermingling co-occurs with inhibition, a barrage is formed (Windram et al., 2016), as it can be seen in figure $\mathbf{3}$ for the three fungal consortia.

The percentages of mycelial growth obtained for each species making up a fungal consortium are shown in table 4. The mycelial growth of each species grown, both alone and within its respective fungal consortium, are presented in figure 4.

\subsection{Degradation of the binary mixture of dyes with consortia under SSF conditions}

In previous studies undertaken in our laboratory, the degradation of $\mathrm{BB}$ and $\mathrm{AR}$ by pure cultures of the same

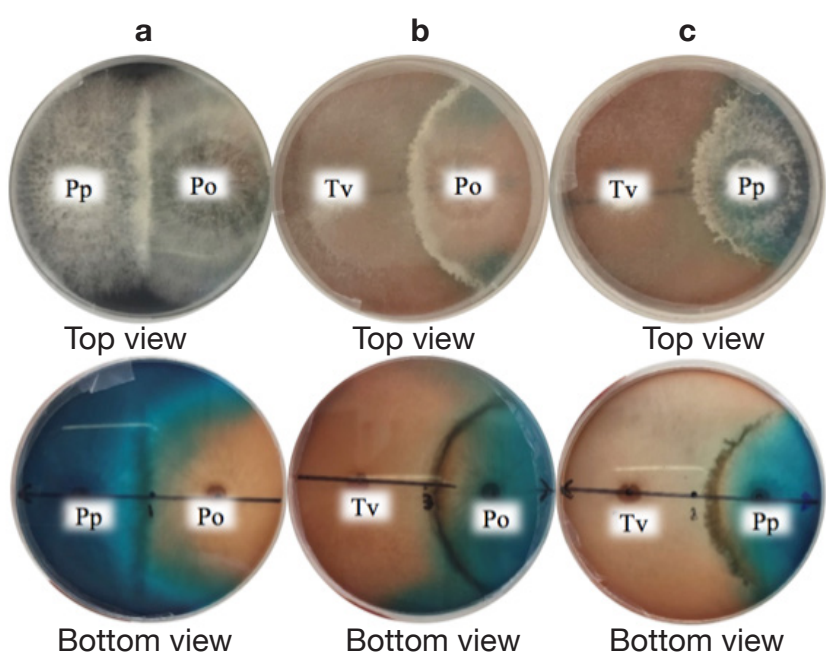

Figure 3. Growth of the consortia after eight days Croissance des consortiums après huit jours.

a. Pleurotus ostreatus - Pleurotus pulmonarius; $\mathbf{b}$. Pleurotus ostreatus - Trametes versicolor; c. Pleurotus pulmonarius - Trametes versicolor.

species assessed in the present study were assessed. The results showed that the degradation percentages were low and inconsistent (data not shown). Therefore, it was decided to use fungal consortia for the degradation of the mixture of dyes to identify any possible synergy between the species. The evaluated consortia did not exhibit inhibition and the percentage of mycelial growth did not decrease below $40 \%$ for any species growing in consortia, indicating that they can grow together in the same media. Thus, the binary mixture of dyes BB-AR was degraded using the consortia $\mathrm{A}, \mathrm{B}$ and $\mathrm{C}$ and the degradation percentage of each dye is shown in table $\mathbf{5}$.

The degradation percentage of BB by the fungal consortia $\mathrm{B}$ and $\mathrm{C}$ were not significantly different according to Scheffé's test. Likewise, the consortia $\mathrm{B}$ and $\mathrm{C}$ are in the same homogeneous group when analyzing the degradation of AR. These results suggest that the fungal consortia that include T. versicolor (B and $C$ ) could be implemented with equal efficiency for treating the mixture of $\mathrm{BB}-\mathrm{AR}$ with a confidence level of $95 \%$.

Table 4. Percentages of mycelial growth - Pourcentages de croissance mycélienne.

\begin{tabular}{|c|c|c|c|c|c|c|}
\hline & \multicolumn{2}{|c|}{ Consortium A } & \multicolumn{2}{|c|}{ Consortium B } & \multicolumn{2}{|l|}{ Consortium C } \\
\hline & $\begin{array}{l}\text { Pleurotus } \\
\text { ostreatus }\end{array}$ & $\begin{array}{l}\text { Pleurotus } \\
\text { pulmonarius }\end{array}$ & $\begin{array}{l}\text { Pleurotus } \\
\text { ostreatus }\end{array}$ & $\begin{array}{l}\text { Trametes } \\
\text { versicolor }\end{array}$ & $\begin{array}{l}\text { Pleurotus } \\
\text { pulmonarius }\end{array}$ & $\begin{array}{l}\text { Trametes } \\
\text { versicolor }\end{array}$ \\
\hline Mycelial growth (\%) & $50.73 \pm 0.93$ & $49.62 \pm 0.35$ & $43.12 \pm 1.16$ & $55.14 \pm 1.88$ & $44.66 \pm 0.27$ & $58.87 \pm 0.76$ \\
\hline
\end{tabular}


a

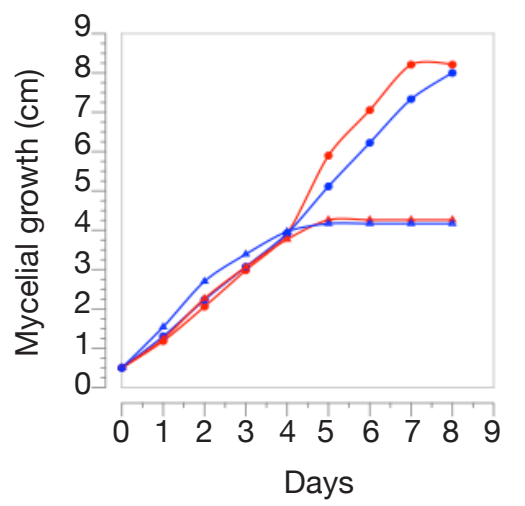

-P. ostreatus $\longrightarrow$ P. ostreatus

P. pulmonarius ${ }_{F} \ldots$ pulmonarius ${ }_{C}$ b

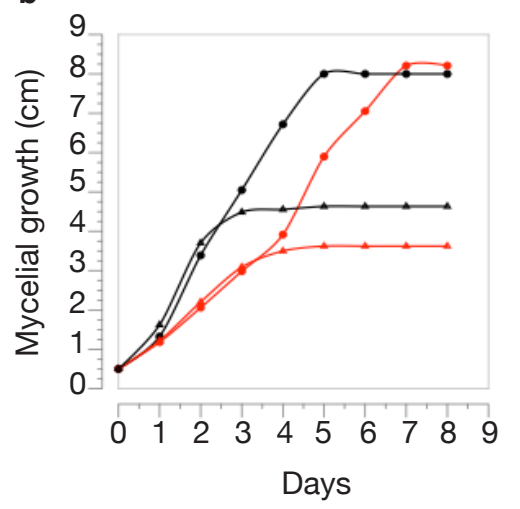

- T. versicolor
P. ostreatus
$F$. versicolor
P. ostreatus
${ }_{C}$ c

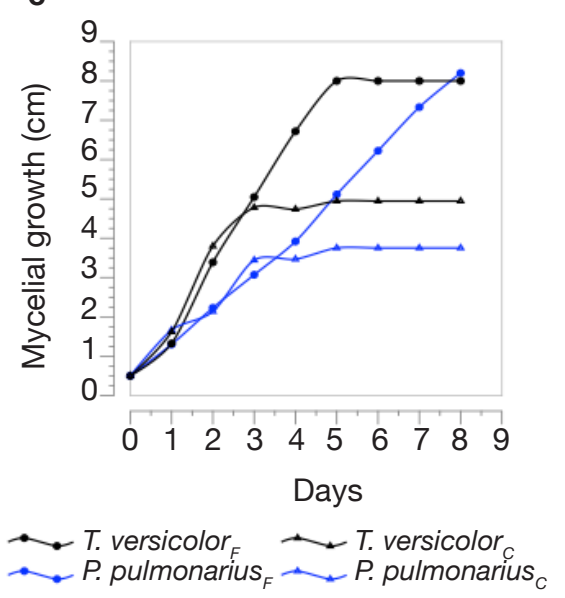

Figure 4. Free mycelial growth $(\mathrm{F})$ and mycelial growth in the consortium $(\mathrm{C})$ for each species - Croissance mycélienne libre $(F)$ et croissance mycélienne dans le consortium $(C)$ pour chaque espèce.

a. Pleurotus ostreatus - Pleurotus pulmonarius; b. Pleurotus ostreatus - Trametes versicolor; c. Pleurotus pulmonarius - Trametes versicolor.

Table 5. Degradation percentage of each dye by the consortia - Pourcentage de dégradation de chaque colorant par les consortiums.

\begin{tabular}{lll}
\hline Consortium & \%D of brilliant blue & $\%$ D of allura red \\
\hline A & $35.31 \pm 13.30^{\mathrm{a}}$ & $51.43 \pm 7.91^{\mathrm{c}}$ \\
$\mathrm{B}$ & $61.44 \pm 2.53^{\mathrm{b}}$ & $65.03 \pm 4.14^{\mathrm{d}}$ \\
$\mathrm{C}$ & $60.23 \pm 6.46^{\mathrm{b}}$ & $56.03 \pm 0.58^{\mathrm{cd}}$ \\
\hline
\end{tabular}

A, B, C: see table 4 - voir tableau 4; the means with the same letter are not significantly different at 5\% (Scheffé's test) - les moyennes surmontées d'une même lettre ne sont pas significativement différentes à $5 \%$ (test de Scheffé).

\section{DISCUSSION}

\subsection{Degradation of the binary mixture of dyes with individual species under SSF conditions}

The maximum degradation of the binary mixture BB AR was $79.57 \%$, reached by T. versicolor. These results agree with those obtained by Martins et al. (2003), who reported degradation percentages higher than $76 \%$ for a mixture of azo dyes using T. versicolor grown in liquid culture. It should be pointed out that in previous studies low degradation percentages, approximately $50 \%$, were obtained for the treatment of $\mathrm{BB}$ using T. versicolor (results not shown in this paper). Therefore, the results reached in the present work for the degradation of the dye mixture $\mathrm{BB}-\mathrm{AR}$ were highly satisfactory and could be attributed to the non-specificity of the secreted ligninolytic enzymes on the structure of the assessed dyes (Coelho-moreira et al., 2013).

Moreover, P. ostreatus reached a degradation of $32.96 \%$ for $\mathrm{BB}$ and $39.97 \%$ for AR. These values are lower than those reported by Zhao \& Hardin (2007) for this species treating azo dyes, which were in the order of $50 \%$. Nevertheless, in their case, the operating conditions were completely different since the culture was performed under submerged conditions and the dyes were treated alone. On the other hand, the degradation achieved with P.pulmonarius was significantly low in comparison to the reported by Tychanowicz et al. (2004). They found degradation percentages over $90 \%$ for azo dyes, such as Congo red, trypan blue and amido black, and in the order of $80 \%$ for triphenylmethane dyes, including methyl violet, methyl green and brilliant cresyl blue. The degradation of those dyes was performed for six days under solid-state fermentation conditions, corncob as solid substrate and glucose and ammonium tartrate as carbon and nitrogen sources, respectively, but the degradation of each dye was evaluated as a single-component (Tychanowicz et al., 2004).

The degradation percentages observed in this work with P.ostreatus and P.pulmonarius were different from those reported in previous studies. When the degradation of dyes with different structure is attempted, the decolorization depends on several factors simultaneously, such as the molecular structure of the dye, the presence of co-substrates, among others (Gupta et al., 2015). Then, the presence of more than one dye could decrease the efficiency of the fungus, the above shows that the degradation is not an additive process. In summary, the differences in the degradation of the mixture of dyes using individual cultures of WRF suggest the incidence of metabolic variations among the evaluated species, which have been widely reported for the bioremediation of both mixtures and individual dyes (Wesenberg et al., 2003). 


\subsection{Evaluation of the interaction between the fungal species}

The fungus T.versicolor colonized most of the medium in the fungal consortia $\mathrm{B}$ and $\mathrm{C}$ as it can be appreciated in figure $\mathbf{3}$. This species usually adopts an r-type strategy, characterized by short periods of rapid growth and a high proliferative rate, which explains its colonization patterns. Hence, their growth is not affected either under nutrient-limited conditions or in the presence of other microorganisms that might generate competition, disturbance, and stress in the surroundings (Zak \& Wildman, 2004).

In the consortium A, both P.ostreatus and $P$. pulmonarius had a percentage of mycelial growth around of $50 \%$, meaning that, in the Petri dish, each species occupies half of the whole space. It is important to point out that $P$. ostreatus and P.pulmonarius had a similar growth behavior, as observed in the figure $\mathbf{4 a}$, where growth curves are almost overlapped. These results indicate that the species had a mycelial growth proportional to their free state and apparently, these fungi do not compete for space. The previous fact suggests that the presence of one species has not a significant effect in the growth of the other one. Qualitatively, in this fungal consortium a decrease of the dye in the medium was not appreciated inside the boundaries of P. pulmonarius (Figure 3a).

The consortia B and $\mathrm{C}$ showed a similar behavior. Thus, in both cases, T. versicolor had a \%MG higher than $55 \%$, exhibiting as it is shown in figures $\mathbf{4 b}$ and $\mathbf{4 c}$ the highest mycelial growth when fermented alone or in consortium. In the early stages of growth (until day 3), the three assessed species displayed a mycelial growth in the fungal consortium comparable to their single state. However, after the third day, the growth of the interacting fungi towards each other was influenced by the competition for space, similar results were found by Molla et al. (2001) in an in vitro assay on Potato Dextrose Agar (PDA) with basidiomycetes (Molla et al., 2001). It was clear that, in both cases, the mycelial growth decreased for each species after the third day when they are compared with the same species freely grown. Nevertheless, $T$. versicolor kept the highest growth rate and because of that, this species could colonize most of the medium. In these situations, a decrease of the dye in the medium was observed (Figures 3b and 3c).

\subsection{Degradation of the binary mixture of dyes with consortia under SSF conditions}

The fungal consortium A, P. ostreatus - P. pulmonarius, showed the lowest degradation percentages for both dyes. However, the degradation reached with P.pulmonarius in the fungal consortium was considerably higher than the one achieved in pure culture. In contrast, the obtained degradation percentage of $\mathrm{BB}$ with $P$. ostreatus was approximately the same that the achieved by the consortium (about $30 \%$ ). Nevertheless, the biodegradation of AR was higher, increasing more than 10 percentage points. The results suggest that the synergy of the species lead to a higher degradation of AR, while the efficiency for BB remained constant.

The fungal consortium B, P.ostreatus T. versicolor, had a good degradation efficacy for both dyes $(>60 \%)$. Comparing the obtained degradation of the mixture in the consortium with that reached by $T$. versicolor alone, it can be concluded that the degradation efficiency decreases when using the fungal consortium. Thus, the expected synergy between the species was not achieved since T. versicolor in pure culture had the highest efficiencies. Particularly, the degradation percentage of both dyes decreases from $79 \%$ to $63 \%$ when T.versicolor was cultured with another species. These findings differ from those reported by Machado et al. (2006), who found that the fungal consortium of WRF, T. villosa - P. sanguineus, increased the degradation percentage of dyes compared to the use of the same species fermented alone. Nevertheless, this study was conducted under submerged fermentation, and as it is well known, liquid cultures are associated with anaerobic processes, that in the most cases lead to the generation of products such as aromatic amines from reduction reactions, compounds of recognized toxicity (Banat et al., 1996).

Finally, with the fungal consortium C, T. versicolor - P.pulmonarius, the results were similar to those obtained by the fungal consortium B. Therefore, it is suggested that the presence of P.pulmonarius reduced the efficiency found with T. versicolor when used in pure culture. The results obtained with the fungal consortia $\mathrm{B}$ and $\mathrm{C}$ allow to suppose that the degradation percentages were mainly due to the activity of $T$. versicolor without reaching a synergy between the species. This kind of behaviors can be seen qualitatively in figure 3 .

Taken together, these results confirm the tendency reported by Windram et al. (2016), when there is mutual intermingling plus inhibition interaction, an antagonistic reaction can occur, because the barrage reaction requires cytoplasmic contact, and this may form abnormal and even lethal fusions between the mycelia (Windram et al., 2016). Besides, the lack of effect of the interaction between the mycelia in the degradation performance could be attributed to the addition of copper that acts as an inductor of the ligninolytic enzymes. It is worth to mention that the type of inoculum can significantly affect the behavior of the different species in the consortium. In this study, the fungi grew in front of each other, 
and because of this reason mutual intermingling plus inhibition interactions were observed. Different types of inoculum, for instance, liquid, pellets or mixing the colonized media can lead to a different behavior. However, further studies that support this issue are needed.

\section{CONCLUSIONS}

A comparison among the individual species showed that the best degradation percentages, approximately $80 \%$, were achieved with $T$. versicolor for both dyes, $\mathrm{BB}$ and AR. Meanwhile, its efficiency decreased almost by 20 percentage points when this species was grown in a fungal consortium.

The evaluation of the interaction between the fungal species showed that mutual intermingling plus inhibition is the prevalent interaction in all the assessed consortia although the species can growth together in the same medium. Moreover, when analyzing the percentage of mycelial growth, neither of the species has decreased its growth below 40\%. Although all the species can grow together in the same medium, T. versicolor has a faster growth, allowing it a faster colonization, and giving it advantages when competing for space and nutrients.

The results as a whole suggest that the use of fungal consortia have not led to a synergy between the species to improve the bioremediation of dyes. This fact could be explained through competition for space and nutrients between the selected species. In SSF processes the microorganisms require a specific area for growing, which becomes restricted when more than one species takes the same substrate for growth.

\section{Acknowledgements}

The authors gratefully acknowledge Universidad Nacional de Colombia - Sede Medellín for its support through the infrastructure of the Experimental Chemistry Laboratory as well as the funding of COLCIENCIAS through the call 745, Project Code 111871250685.

\section{Bibliography}

Baldrian P. \& Gabriel J., 2002. Copper and cadmium increase laccase activity in Pleurotus ostreatus. FEMS Microbiol. Lett., 206(1), 69-74.

Banat I.M., Nigam P., Singh D. \& Marchant R., 1996 . Microbial decolorization of textile-dye-containing effluents: a review. Bioresour. Technol., 58, 217-227.

Castillo M.R., Gutierrez-Correa M., Linden J.C. \& Tengerdy R.P., 1994. Mixed culture solid substrate fermentation for cellulolytic enzyme production. Biotechnol.Lett., 16(9), 967-972.
Chander M. \& Arora D.S., 2007. Evaluation of some whiterot fungi for their potential to decolourise industrial dyes. Dyes Pigments, 72, 192-198.

Coelho-moreira J.S. et al., 2013. Involvement of ligninmodifying enzymes in the degradation of herbicides. In: Price A., ed. Herbicides. Advances in research. London: IntechOpen, 165-187.

de Mendiburu F., 2015. Agricolae: statistical procedures for agricultural research. $\mathrm{R}$ Package version 1.2-3.

Dyes - pigments by Standardcon, 2018. Synthetic dyes, www.dyes-pigments.standardcon.com/synthetic-dyes. $\mathrm{html},(02 / 06 / 2018)$.

Echavarria-Alvarez A.M. \& Hormaza-Anaguano A., 2014. Flower wastes as a low-cost adsorbent for the removal of acid blue 9. Dyna, 81(185), 131-137.

Forgacs E., Cserháti T. \& Oros G., 2004. Removal of synthetic dyes from wastewaters: a review. Environ. Int., 30, 953-971.

Galhaup C. \& Haltrich D., 2001. Enhanced formation of laccase activity by the white-rot fungus Trametes pubescens in the presence of copper. Appl. Microbiol. Biotechnol., 56(1-2), 225-232.

Gupta V.K., Mittal A., Krishnan L. \& Mittal J., 2006. Adsorption treatment and recovery of the hazardous dye, brilliant blue FCF, over bottom ash and de-oiled soya. J. Colloid Interface Sci., 293, 16-26.

Gupta V.K. \& Suhas, 2009. Application of low-cost adsorbents for dye removal. A review. J. Environ. Manage., 90(8), 2313-2342.

Gupta V.K., Khamparia S., Tyagi I. \& Malviya A., 2015. Decolorization of mixture of dyes: a critical review. Global J. Environ. Sci. Manage., 1(1), 71-94.

Gutierrez-Correa M., Portal L., Moreno P. \& Tengerdy R.P., 1999. Mixed culture solid substrate fermentation of Trichoderma reesei with Aspergillus niger on sugar cane bagasse. Bioresour. Technol., 68, 173-178.

Hansen W.H., Fitzhugh O.G., Nelson A.A. \& Davis K.J., 1966. Chronic toxicity of two food colors, brilliant blue FCF and indigotine. Toxicol. Appl. Pharmacol., 8(1), 29-36.

Hodges M., 1984. Allura red. Developmental and psychotoxic effects? Food Chem. Toxicol., 22(11), 913928.

Ijoma G.N. \& Tekere M., 2017. Potential microbial applications of co-cultures involving ligninolytic fungi in the bioremediation of recalcitrant xenobiotic compounds. Int. J. Environ. Sci. Technol., 14(8), 17871806.

Jaramillo A.C., Echavarría A.M. \& Hormaza A., 2013. Box-Behnken design for optimizing the acid blue dye adsorption on flower wastes. Ingenieria Cienc., 9, 7591.

Jaramillo A., Jiménez S., Merino A. \& Hormaza A., 2014. Obtención de un inóculo fúngico para la degradación de un colorante azo por fermentación en estado sólido. Rev. U.D.C.A Actual. Divulg. Cient., 17(2), 577-586. 
Jaramillo A.C., Cobas M., Hormaza A. \& Sanromán M.Á., 2017. Degradation of adsorbed azo dye by solid-state fermentation: improvement of culture conditions, a kinetic study, and rotating drum bioreactor performance. Water Air Soil Pollut, 228:205.

Jiménez S., Velásquez C., Mejía F. \& Hormaza A., 2017. Removal of the mixture of azo dyes allura red tartrazine by adsorption onto corncob. In: Proceedings of the International conference of recent trends in environmental science and engineering (RTESE'17), August 23-25, 2017, Toronto, Canada, Paper No. 141.

Kausar H. et al., 2010. Development of compatible lignocellulolytic fungal consortium for rapid composting of rice straw. Int. Biodeterior. Biodegrad., 64(7), 594600.

Kuhar F., Castiglia V. \& Levin L., 2015. Enhancement of laccase production and malachite green decolorization by co-culturing Ganoderma lucidum and Trametes versicolor in solid-state fermentation. Int. Biodeterior. Biodegradation, 104, 238-243.

Machado K.M.G. et al., 2006. Biodegradation of reactive textile dyes by basidiomycetous fungi from Brazilian ecosystems. Brazilian J. Microbiol., 37, 481-487.

Martins M.A.M., Lima N., Silvestre A.J.D. \& Queiroz M.J., 2003. Comparative studies of fungal degradation of single or mixed bioaccessible reactive azo dyes. Chemosphere, 52, 967-973.

Membrillo I. et al., 2008. Effect of substrate particle size and additional nitrogen source on production of lignocellulolytic enzymes by Pleurotus ostreatus strains. Bioresour. Technol., 99, 7842-7847.

Molla A.H. et al., 2001. In vitro compatibility evaluation of fungal mixed culture for bioconversion of domestic wastewater sludge. World J. Microbiol. Biotechnol., 17, 849-856.

Moreno A., Figueroa D. \& Hormaza A., 2012. Diseño estadístico para la remoción eficiente del colorante rojo 40 sobre tusa de maíz. Produccion Limpia, 7(2), 9-19.

$\mathrm{R}$ Development Core Team, 2015. R: a language and environment for statistical computing. Vienna: the $\mathrm{R}$ Foundation for Statistical Computing.

Robinson T., Chandran B. \& Nigam P., 2002. Effect of pretreatments of three waste residues, wheat straw, corncobs and barley husks on dye adsorption. Bioresour. Technol., 85, 119-124.

Robinson T. \& Nigam P.S., 2008. Remediation of textile dye waste water using a white-rot fungus Bjerkandera adusta through solid-state fermentation (SSF). Appl. Biochem. Biotechnol., 151(2-3), 618-628.

Singhania R.R., Patel A.K., Soccol C.R. \& Pandey A., 2009. Recent advances in solid-state fermentation. Biochem. Eng. J., 44, 13-18.
Soylak M.,Unsal Y.E.\&Tuzen M.,2011.Spectrophotometric determination of trace levels of allura red in water samples after separation and preconcentration. Food Chem. Toxicol., 49(5), 1183-1187.

Sulyman M., Namiesnik J. \& Gierak A., 2017. Low-cost adsorbents derived from agricultural by-products/wastes for enhancing contaminant uptakes from wastewater: a review. Polish J. Environ. Stud., 26(2), 479-510.

Thomas L., Larroche C. \& Pandey A., 2013. Current developments in solid-state fermentation. Biochem. Eng. J., 81, 146-161.

Turabik M., 2008. Adsorption of basic dyes from single and binary component systems onto bentonite: simultaneous analysis of Basic Red 46 and Basic Yellow 28 by first order derivative spectrophotometric analysis method. J. Hazard. Mater., 158, 52-64.

Tychanowicz G.K., Zilly A., De Souza C.G.M. \& Peralta R.M., 2004. Decolourisation of industrial dyes by solid-state cultures of Pleurotus pulmonarius. Process Biochem., 39(7), 855-859.

Van Soest P.J. \& Wine R.H., 1968. Determination of lignin and cellulose in acid-detergent fiber with permanganate. J. Assoc. Off. Anal. Chem., 51, 780-785.

Verma P. \& Madamwar D., 2002. Production of ligninolytic enzymes for dye decolorization by cocultivation of white-rot fungi Pleurotus ostreatus and Phanerochaete chrysosporium under solid-state fermentation. Appl. Biochem. Biotechnol., 102(1-6), 109-118.

Villada Y. \& Hormaza A., 2015. Análisis simultáneo de la remoción de Azul Brillante y Rojo 40 mediante espectrofotometría de derivadas. Ingenieria Desarrollo, 33(1), 38-58.

Vorhees C.V. et al., 1983. Developmental toxicity and psychotoxicity of FD and $\mathrm{C}$ red dye no. 40 (allura red AC) in rats. Toxicology, 28(3), 207-217.

Wesenberg D., Kyriakides I. \& Agathos S.N., 2003. Whiterot fungi and their enzymes for the treatment of industrial dye effluents. Biotechnol. Adv., 22, 161-187.

Windram O., Stoker C. \& Denby K., 2016. Overview of plant defence systems: lessons from Arabidopsis-Botrytis cinerea systems biology. In: Fillinger S. \& Elad Y., eds. Botrytis - the fungus, the pathogen and its management in agricultural systems. Cham, Switzerland: Springer, 335-360.

Zak J.C. \& Wildman H.G., 2004. Fungi in stressful environments. In: Mueller G., Foster M. \& Bills G., eds. Biodiversity of fungi. Inventory and monitoring methods. Elsevier Inc., 303-315.

Zhao X.\& Hardin I.R., 2007. HPLC and spectrophotometric analysis of biodegradation of azo dyes by Pleurotus ostreatus. Dyes Pigments, 73(3), 322-325.

(45 ref.) 